\title{
A dinâmica da migração internacional qualificada para o estado de São Paulo no século XXI: os espaços da migração dos "trabalhadores do conhecimento"
}

\author{
The dynamics of the international skilled migration \\ to the state of São Paulo in the 21st century: \\ migration spaces of "knowledge workers"
}

Jóice de Oliveira Santos Domeniconi Rosana Baeninger

\begin{abstract}
Resumo
0 cenário das migraç̧ões internacionais no século XXI condiz com o estudo de modalidades migratórias (Patarra, 2005) que se desenvolvem nos mesmos espaços de migração (Baeninger, 2014a), como a migração qualificada (Martine 2005). Em uma sociedade permeada por mudanças tecnológicas (Pellegrino, 2003) e pela intensidade da internacionalização do capital e da mobilidade da força de trabalho (Sassen, 1988), a compreensão do fenômeno migratório envolve, também, suas dimensões espaciais (Baeninger, 2014a). Os dados da Relação Anual de Informações Sociais sobre a inserção dos imigrantes qualificados no mercado de trabalho formal permitem apreender, assim, uma formalização crescente desses profissionais, enquanto trabaIhadores do conhecimento (Mello, 2007), presentes nos diferentes municípios do estado de São Paulo, para além da região metropolitana.
\end{abstract}

Palavras-chave: migração internacional; migração qualificada; trabalhadores do conhecimento; espaços da migração e estado de São Paulo-Brasil.

\begin{abstract}
The setting of international migration in the 21st century is aligned with the study of migration patterns (Patarra, 2005) that develop in the same migratory spaces (Baeninger, 2014), like skilled migration (Martine, 2005). In a society permeated by technological changes (Pellegrino, 2003) and by the intensity of the internationalization of capital and labor mobility (Sassen, 1988), the understanding of the migration phenomenon also involves its spatial dimensions (Baeninger, 2014). Data from the Annual Social Information Report on the insertion of skilled immigrants into the formal labor market allow us to perceive an increasing formalization of these professionals, as knowledge workers (Mello, 2007) present in different municipalities of the state of São Paulo, beyond the Metropolitan Region.
\end{abstract}

Keywords: International migration; skilled migration; knowledge workers; migration spaces and state of São Paulo-Brazil. 


\section{Introdução}

0 panorama das migrações internacionais no século XXI condiz com o estudo de diferentes modalidades migratórias (Patarra, 2005) que se desenvolvem nos mesmos espaços de migração (Baeninger, 2014a), entre elas, a migração de profissionais altamente qualificados (Martine, 2005), compreendidos em termos de escolaridade e ocupação. Essa dinâmica se torna particular, sobretudo, em uma sociedade permeada pelas mudanças nas formas de comunicação, transporte e difusão das informações (Pellegrino, 2003) e, ao mesmo tempo, pela maior intensidade da internacionalização do capital e da mobilidade da força de trabaIho (Sassen, 1988). Como adverte Baeninger (2014a), a compreensão do fenômeno migratório no contexto atual envolve necessariamente o estudo das dimensões espaciais desse processo, qual seja, a relação entre a esfera nacional e internacional, local e global.

Dessa forma, este trabalho procura analisar os fluxos migratórios recentes de profissionais altamente qualificados que, de fato, conseguiram se inserir no mercado formal de trabalho do estado de São Paulo, a partir da discussão sobre migração qualificada (Martine, 2005) e circulação de cérebros (Saxenian, 2002). Assim, com o objetivo de aproximar 0 debate internacional (OCDE, 1995) ao contexto nacional, adota-se a categoria operacional de trabalhadores do conhecimento (Florida, 2014 e Mello 2007), uma possibilidade de análise desses profissionais baseada no nível de escolaridade e nas ocupações segundo os padrões nacionais.
Para tanto, as análises tomam como base os dados da Relação Anual de Informações Sociais, ainda que estes apresentem algumas limitações por se tratarem de registros de trabalho formal e, consequentemente, não compreenderem profissionais que atuam na informalidade ou como autônomos. Buscam-se avaliar, sobretudo, a composição e a distribuição espacial no estado de São Paulo desses vínculos, de modo a estabelecer um panorama dessa migração internacional altamente qualificada no século XXI em diferentes espaços da migração (Baeninger, 2014a).

\section{A migração internacional qualificada no século XXI: breves considerações teóricas}

As particularidades da dinâmica migratória no século XXI envolvem, em grande parte, a compreensão das tensões entre os diferentes níveis do debate, internacional, nacional e local, principalmente, tendo em vista a perspectiva de que "os movimentos migratórios internacionais constituem a contrapartida da reestruturação territorial planetária - que, por sua vez, está intrinsecamente relacionada à reestruturação econômico-produtiva em escala global" (Patarra, 2005, p. 24). Patarra ressalta em sua análise, portanto, que dentro da discussão sobre "migração internacional" estariam envolvidos "processos e fenômenos distintos", os quais corroboram com a ideia de que existem diferentes modalidades migratórias emergentes "no contexto do capitalismo 
internacional e próprias da globalização atual" (ibid., p. 25).

Para Chesnais (1996), dois fatores principais seriam responsáveis por essas mudanças nas formas de internacionalização do capital e sua consequente globalização nos anos 1980. 0 primeiro seria a desregulamentação financeira e sua expansão em nível global; e o segundo diz respeito ao desenvolvimento de novas tecnologias de informação e telecomunicação. 0 autor observa, ainda, que, de forma adjacente à desregulamentação, houve também um intenso processo de liberalização econômica, o qual, juntamente com o avanço tecnológico, teria dado margem a maior propensão à mobilidade do capital, interna e internacionalmente. Assim, seria possível considerar que a internacionalização do capital, enquanto fase de sua mundialização, é um dos elementos centrais na determinação das relações sociais e da dinâmica populacional no século XXI.

Chesnais (ibid.) acrescenta que a adoção de novas formas de produção e gerenciamento, assim como a flexibilização dos contratos, acabaram por favorecer a terceirização do trabalho e teriam, inclusive, corroborado com a conciliação entre o capital altamente concentrado e a descentralização de seus espaços de valorização. Martine (2005, p. 4) observa que essa "nova forma de organização da produção" capitalista estaria profundamente relacionada à adoção do chamado "Consenso de Washington", 1 modelo defendido agressivamente nas décadas de 1980 e 1990 por instituições internacionais para o crescimento econômico dos países em desenvolvimento .

A internacionalização envolveria, assim, não apenas o "comércio exterior, o investimento externo direto e os fluxos internacionais de capital", mas também as transferências de tecnologias, "os movimentos internacionais de pessoal qualificado e os fluxos de informações e dados transfronteiras" (OCDE apud Chesnais, 1996, p. 43).

Sassen (1988) avança no debate, ao ponderar que a dinâmica de reprodução e 0 avanço internacional do capital através do investimento externo direto seriam fatores centrais ao desenvolvimento de relações que favoreceriam os fluxos migratórios, ou seja, para a formação de um "conjunto de imigrantes em potencial" (p. 118; tradução livre). ${ }^{2}$ Ao passo que "a generalização das relações de mercado tem apresentado historicamente um efeito de dissolução nas estruturas tradicionais do trabalho e promovido a formação de trabalhadores imigrantes" (ibid., p. 119; tradução livre). ${ }^{3}$

Como destaca Hagiu (2010),

colocar o capital em outras regiões do mundo envolve, necessariamente, a migração de pessoal. As corporações transnacionais favorecem a reunião da força de trabalho com o capital fazendo o movimento do trabalho até o capital ou a transferência de capital para áreas com excedente de força de trabalho. (p. 345; tradução livre) ${ }^{4}$

Martine (2005), porém, observa que, apesar da "generalização do livre-comércio, o crescimento no número e tamanho de empresas transnacionais que funcionam como sistemas de produção integrados e a mobilidade de capitais", (p. 4) serem fatores que corroborariam para o aumento da migração, esta se encontra muitas vezes "limitada e restrita dentro do contexto atual" (p. 5). 0 autor defende que, ainda que exista um forte incentivo à migração 
internacional em um contexto de globalização "parcial e inacabada" (p. 3),

0 capital humano é um fator de produção que, formalmente, não tem livre trânsito entre fronteiras nos dias de hoje; não existe um "mercado global de trabalho". As fronteiras abrem-se para o fluxo de capitais e mercadorias, mas estão cada vez mais fechadas aos migrantes. (lbid., p. 8)

Não obstante, Tilly (1976) já apresentava, no debate sobre migração internacional na década de 1970, as particularidades da migração de profissionais qualificados. 0 autor aponta, em seus trabalhos, a "migração de carreira", composta por movimentos internacionais de profissionais de acordo com oportunidades ocupacionais em instituições como empresas, estados e mercados de trabalho a partir dos anos 1970.

A particularidade da migração internacional qualificada contemporânea resultaria, portanto, "não apenas de seu menor volume e visibilidade social, quando comparado com outros movimentos migratórios, mas também de sua relação direta com os movimentos de capitais e das estratégias provisórias que frequentemente empregam" (Peixoto, 2001, p. 1049; tradução livre). ${ }^{5}$ Fica clara a necessidade de avaliar a migração internacional de profissionais qualificados em suas diferentes facetas e complexidades; sobretudo, quando se têm em mente a influência de uma gama diversificada de atores no cenário internacional e o papel central dos fluxos migratórios na expansão da dinâmica capitalista para além das fronteiras nacionais, ainda que sejam também por ela influenciados.

0 movimento do capital humano enquanto fator de produção estaria, portanto, inserido em uma dinâmica maior de movimentos populacionais diversos, os quais se relacionam, muitas vezes, ao próprio avanço do capitalismo (em tamanho e proporção) (Braudel, 1987) e ao consequente aumento da seletividade e competitividade no mercado de trabaIho (Brito, 1995). Baeninger (2014a) avança ao considerar que

[...] A história da imigração se vincula à expansão do capitalismo (Braudel, 1987) com a circulação de capital, mercadorias e pessoas, construindo um excedente populacional. No contexto atual, é importante destacar que esse excedente populacional corresponde às necessidades geradas tanto na área de origem como na área de destino (Baeninger, 2012), compondo um movimento transnacional, que acompanha o capital e a inserção das localidades na divisão social e territorial do trabalho em âmbito nacional e internacional. (p. 2)

Sayad (1998) adverte que a migração envolve, em primeiro lugar, um "[...] deslocamento de pessoas no espaço, e antes de mais nada no espaço físico"; espaço este que também deve ser qualificado "socialmente, economicamente, politicamente, culturalmente" ( p. 15).

A partir disso, como argumenta Baeninger (2014a), "à medida que as localidades se inserem na lógica global" é possível observar maior intensidade e diversidade das migrações internacionais. Esse processo passaria a ter sua "velocidade equiparada à da mobilidade do capital", o que leva, consequentemente, a mudanças também nas dinâmicas de "desenvolvimento e constituição" do mercado de trabalho (p. 6) e na distribuição dos "espaços da migração interna e internacional" desses fluxos (p. 10). 
Destaca-se, então, a relevância das "dimensões espaciais", próprias do espaço urbano ou do regional (Brandão, 2007, p. 216) na compreensão do fenômeno migratório, ou seja, "a forma histórica que tomaram a constituição e a reprodução social das classes sociais em sua expressão espacial" (ibid., p. 217). É necessário, portanto, ter em mente como se constituem e definem os espaços e suas esferas de decisão, os quais, em grande parte, são determinados a partir da dinâmica de reprodução do capital em níveis local e global (ibid.) por meio da inserção diferenciada dos lugares ocupados pelos países de origem e destino dos movimentos migratórios na "divisão social e territorial do trabalho" (Baeninger, 2014a, p. 2).

Nesse cenário, este artigo busca compreender os fluxos migratórios internacionais no século XXI em sua multiplicidade de processos e contextos particulares, os quais se inserem em uma lógica maior de reestruturação econômico-produtiva internacionalizada (Patarra, 2005), em que diferentes locais de origem e destino se relacionam e se conectam a diferentes fluxos migratórios com características próprias ao seu tempo e lugar na reprodução social aos moldes capitalistas.

\section{Os trabalhadores do conhecimento na migração qualificada do século XXI}

Assim, para que seja possível analisar os diferentes fluxos migratórios internacionais de profissionais altamente qualificados a partir de sua complexidade, é importante avaliar, primeiramente, os parâmetros comparativos que discorrem sobre o tema.

Parte-se, então do "Manual Canberra", 6 criado com o objetivo de estabelecer um aparato de análise e delimitação dos "Recursos Humanos dedicados a Ciência e Tecnologia (RHCT)" OCDE, 1995, p. 2; tradução livre). ${ }^{7} 0$ grupo caracterizaria os profissionais altamente qualificados que tenham "concluído com êxito a educação em nível terciário num domínio de ciência e tecnologia" ou, ainda que não detenham o mesmo nível de qualificação, estejam "empregados em uma ocupação de ciência e tecnologia na qual as qualificações acima sejam normalmente exigidas" (ibid., p. 16; tradução livre). ${ }^{8} 0$ termo $\mathrm{RHCT}^{9}$ descreveria, portanto, uma "força de trabalho qualificada especial" (ibid., p. 8; tradução livre). ${ }^{10}$ Dessa forma, o Manual avança ao definir trabalho qualificado com base tanto no nível de instrução, quanto na ocupação exercida pelos profissionais (OCDE, 1995). Assim, em trabalhos empíricos é comum o uso de proxies relativas à educação ou à ocupação desses indivíduos (Auriol e Sexton, 2001).

Ademais, existem distinções na delimitação do termo "qualificado", pois, no que diz respeito às disposições sobre migração internacional, trata-se de uma "qualificação formal e corresponde a uma classificação internacional existente e amplamente utilizada, a Classificação Internacional de Educação (CIE)" (ibid., p. 14; tradução livre). ${ }^{11}$

Como observam Daugeliene e Marcinkeviciene (2009), a migração internacional de trabalhadores altamente qualificados é composta por diversos fluxos migratórios. Contudo, deve-se destacar o papel central exercido 
pela parcela de trabalhadores do conhecimento na sociedade atual. Segundo as autoras,

os trabalhadores do conhecimento são um dos elementos mais importantes, sendo responsáveis por demonstrar a capacidade do país de competir no mercado global. Além disso, eles poderiam ser definidos como o eixo motor da "circulação de cérebros". (Ibid., p. 50; tradução livre $)^{12}$

Ademais, esses profissionais apresentam uma qualificação diferenciada, capaz de "converter conhecimento, inteligência, sabedoria e ideias em produtos inovadores ou serviço tangível" (Daugeliene, 2007 apud Daugeliene e Marcinkeviciene, 2009, p. 50). ${ }^{13}$ Nesse sentido, a imigração internacional desses trabalhadores seria estratégica, visto que, como apontado pelo Fórum Econômico Mundial (FMI), "o contexto globalizado atual demanda economias capazes de nutrir bolsões de trabalhadores bem-educados, os quais apresentem uma capacidade elevada de adaptação perante um ambiente de constantes mudanças" (The Global Competitiveness Report apud ibid.). ${ }^{14}$

Dessa forma, a migração internacional de profissionais altamente qualificados estaria inserida, no contexto atual, em uma lógica mais complexa de competitividade entre os diferentes espaços de valorização do capital em nível global; sendo, inclusive, afetada por um conjunto diverso de fatores histórico-estruturais que determinam as condições de alocação produtiva e, consequentemente, o papel desses espaços na divisão internacional do trabaIho. Com base nesse ponto de vista, Saxenian (2002) argumenta que, na circulação de cérebros, a migração qualificada tem demonstrado ser plausível obter benefícios para os locais de origem e destino dos imigrantes, desenhando, assim, novas possibilidades de desenvolvimento econômico.

No entanto, muitos dos estudos desenvolvidos no tema da circulação dizem respeito aos fluxos migratórios internacionais de países em desenvolvimento ou mesmo não desenvolvidos para países altamente desenvolvidos, como Estados Unidos, Japão e diversas nações na Europa. Dada a atual configuração do cenário internacional, cada vez mais baseada na reestruturação produtiva e na inserção de diferentes espaços na lógica de reprodução do capital, produtivo e financeiro, seria errôneo ignorar a diversidade de fluxos migratórios envolvida nesse processo.

Como aponta Solimano (2013)

A diversidade de migrantes qualificados hoje [...] está ligada à diversidade das rotas migratórias e "ecossistemas" que incentivam a mobilidade internacional e 0 sucesso na carreira. Os circuitos em que esse setor se desenvolve são [...] espaços que contam com mecanismos próprios, políticas e processos que facilitam a mobilidade da mão de obra qualificada que necessitam contratar, o que inclui formas de contratação, salários atraentes, benefícios de seguro de saúde e muitas vezes outras características especiais. (Apud OIM, 2016, p. 37) ${ }^{15}$

Nesse contexto, o conhecimento seria, de acordo com a OIM (2016), um bem estratégico à geração de riqueza em nível internacional, daí a valorização cada vez maior das áreas de criação de bens e serviços com base em ciência e tecnologia. A competitividade ganha, então, um aspecto sistêmico e o conhecimento, espaço na dinâmica produtiva internacional com o constante incentivo à inovação. 
No entanto, é importante ponderar que

[...] As categorias da migração qualificada tornaram-se mais complexas e diversificadas nas últimas décadas, envolvendo desde a clássica migração laboral de trabalhadores qualificados, a partir de uma experiência laboral, aos profissionais independentes com formação universitária nas áreas de administração de empresas, finanças, negócios e afins; os gerentes, executivos ou funcionários especializados de empresas multinacionais que se deslocam dentro da empresa, o setor altamente qualificado em ciência, tecnologia, engenharia e matemática [...] incluindo a área de tecnologia da informação e os estudantes de educação superior que vão estudar no exterior. (Ibid., p. 186) ${ }^{16}$

0 conhecimento passaria, então, a ser gerido pela dinâmica financeira e produtiva de grandes corporações multinacionais, que exercem uma demanda progressiva do fator trabalho em sua forma altamente especializada, com um nível educacional elevado e capaz de atuar em ocupações consideradas essenciais a desenvolvimento, inovação e geração de novas tecnologias (ibid.). Desse modo,esses profissionais contribuiriam "ao desenvolvimento econômico, já que se trata de pessoas que têm um grande potencial para gerar valor econômico, científico, tecnológico e cultural devido a suas habilidades e conhecimentos, por isso são conhecidos como 'migrantes de alto valor'" (ibid., p. 188; tradução livre). ${ }^{17}$

Nesse sentido, buscar-se-á compreender a dinâmica socioespacial de inserção da migração internacional qualificada no mercado de trabalho brasileiro a partir do conceito operacional de trabalhadores do conhecimento (Florida, 2014 e Mello, 2007), uma forma de trabalhar com a discussão acerca dos Recursos
Humanos dedicados à Ciência e Tecnologia (RHCT) aplicada ao contexto nacional, sobretudo, no que diz respeito às bases de dados estatísticos disponíveis e às categorias nacionais de ocupação. Levam-se em conta, sobretudo, as especificidades e heterogeneidade dos fluxos migratórios internacionais de profissionais altamente qualificados para o Brasil, mais especificamente para São Paulo.

Florida (2014) $)^{18}$ traz, para os trabalhadores do conhecimento, a definição da classe criativa: composta por profissionais capazes de exercer um papel dominante do ponto de vista econômico, social e político. 0 autor delimita essa nova classe criativa como sendo formada por profissionais e técnicos de destaque em diferentes áreas que envolvam conhecimento e análise simbólica, os quais "agregam valor econômico por meio de sua criatividade" (ibid., posição 490). ${ }^{19} \mathrm{~A}$ definição operacional do autor para os trabalhadores do conhecimento está dividida entre um núcleo "duro" e uma esfera mais "fluida" com possíveis conexões na estrutura ocupacional desses profissionais. A estrutura da classe criativa de Florida inclui: Núcleo Supercriativo - ocupações relacionadas à computação e à matemática; à arquitetura e às engenharias, às ciências da vida, físicas e sociais; à educação, ao treinamento, à biblioteconomia, às artes, ao design, ao entretenimento, aos esportes e à mídia; e Profissionais Criativos - ocupações relacionadas à administração e à gestão; aos negócios e às operações financeiras; ao sistema legal; à prática e à técnica dos cuidados com a saúde; à gestão de vendas e ao atacado.

Nesse sentido, Mello (2007) avança nas análises, buscando o agrupamento de ocupações para o trabalhador do conhecimento 
em Campinas-SP, a partir dos critérios de Florida (2014) e com base nas informações do Código Brasileiro de Ocupações (CBO). ${ }^{20} 0$ autor adiciona, à classe criativa, a categoria "Outros", constituída, principalmente, por profissionais da área de educação, responsáveis pela formação dos profissionais criativos. Assim, é a partir desse agrupamento de ocupações que analisaremos a imigração internacional do trabalhador do conhecimento em São Paulo no início do século XXI.

Ademais, os dados utilizados no decorrer do trabalho dizem respeito aos vínculos ativos de emprego no mercado formal brasileiro presentes na Relação Anual de Informações Sociais (Rais) do Ministério do Trabalho e Previdência Social (MTPS). Os dados obtidos nessa base representam registros administrativos de responsabilidade do empregador e com periodicidade anual. Há uma abrangência nacional que pode ser desagregada por país, grandes regiões, unidades da federação e municípios. $A$ Rais apresenta, portanto, informações de estoque (número de empregos) e de movimentação (IBGE). De modo que, entre suas limitações, ressalta-se que os registros dizem respeito aos vínculos de trabalho estabelecidos pelos profissionais com as empresas e os ativos em 31 de dezembro, não ao volume de imigrantes, visto que uma pessoa pode vir a apresentar mais de um emprego formal. Além disso, existem possíveis omissões, erros de preenchimento ou divulgação de dados fora do período de declaração por parte dos empregadores (IBGE) e a base não contempla dados sobre profissionais autônomos e imigrantes na informalidade.

Apesar desses limites, é possível captar os vínculos de trabalhadores estrangeiros, bem como informações socioeconômicas relevantes para a composição do perfil desse contingente e de sua inserção no mercado formal de trabaIho. Essa fonte de dados contempla em média a $97 \%$ do universo de registros formais com base na Consolidação das Leis do Trabalho (CLT) (Palermo, Oliveira e Lopes, 2015, pp. 19-21).

Leva-se em consideração, portanto, que tais dados representam os vínculos ativos estabelecidos pelos imigrantes com as empresas até 31 de dezembro do ano anterior ao considerado, e o uso de um marco temporal preestabelecido condiz "com o intuito de evitar a superenumeração" dos dados estudados (Pereira, 2015, p. 65). Dessa forma, é possível considerar que a Rais capta grande parte da imigração qualificada para o Brasil no início do século XXI, uma vez que se trata, em sua maioria, de uma imigração documentada e inserida no mercado de trabalho formal do País.

A partir disso, para identificar os Imigrantes Trabalhadores do Conhecimento (ITC), foram selecionadas as seguintes variáveis dos microdados: CBO, 2002; emprego em 31/12; faixa etária; escolaridade após 2005; idade; municípios por Unidades Federativas (UF), nacionalidade; sexo. ${ }^{21}$ Com isso, busca-se analisar quais as principais características da população migrante qualificada inserida no mercado de trabalho formal segundo os critérios de análise dos "imigrantes trabalhadores do conhecimento", principalmente, o nível escolaridade e a ocupação segundo a CBO, 2002. Logo, foram selecionados os vínculos de trabalho ativos, para estrangeiros entre 10 e 65 anos ou mais de idade, registrados no mercado de trabalho formal do estado de São Paulo, que apresentassem uma escolaridade maior ou igual ao ensino superior completo ${ }^{22}$ e ocupações condizentes com a metodologia utilizada (Quadro 1). 
Quadro 1 - Ocupações relativas ao trabalhador do conhecimento de acordo com o Código Brasileiro de Ocupações - Classe Criativa

\begin{tabular}{|c|c|}
\hline $\begin{array}{l}\text { Código Brasileiro } \\
\text { e Ocupação (CBO) }\end{array}$ & Ocupações da Categoria Núcleo Supercriativo \\
\hline 2011 & Profissionais de Bioenergia e Engenharia Genética \\
\hline 2021 & Engenheiros Mecatrônicos \\
\hline 2111 & Profissionais da Matemática \\
\hline 2112 & Profissionais da Estatística \\
\hline 2122 & Engenheiros em Computação-Desenvolvimento de Software \\
\hline 2123 & Especialista em Informática \\
\hline 2124 & Analista de Sistemas \\
\hline 2131 & Físicos \\
\hline 2132 & Químicos \\
\hline 2133 & Profissionais do espaço e da Atmosfera \\
\hline 2134 & Geólogos e Geofísicos \\
\hline 2140 & Engenheiros Ambientais e afins \\
\hline 2141 & Arquitetos \\
\hline 2142 & Engenheiros Civis e afins \\
\hline 2143 & Engenheiros Eletroeletrônicos e afins \\
\hline 2144 & Engenheiros Mecânicos \\
\hline 2145 & Engenheiros Químicos \\
\hline 2146 & Engenheiros Metalurgistas e de Materiais \\
\hline 2147 & Engenheiros de Minas \\
\hline 2148 & Engenheiros Agrimensores e de Cartografia \\
\hline 2149 & Engenheiros Industriais, de produção e segurança \\
\hline 2211 & Biólogos e afins \\
\hline 2221 & Engenheiros Agrossivilpecuários \\
\hline 2511 & Profissionais em Pesquisa e Análise Antropológica e Sociológica \\
\hline 2512 & Profissionais em Pesquisa e Análise Econômica \\
\hline 2513 & Profissionais em Pesquisa e Análise Histórica e Geográfica \\
\hline 2514 & Filósofos e Cientistas Políticos \\
\hline 2531 & Profissionais de Relações Públicas, Publicidade, Mercado e Negócios \\
\hline 2611 & Profissionais do Jornalismo \\
\hline 2612 & Profissionais da Informação \\
\hline 2613 & Arquivologistas e Museólogos \\
\hline 2614 & Filólogos, Intérpretes e Tradutores \\
\hline 2615 & Profissionais da Escrita \\
\hline 2616 & Especialistas em Editoração \\
\hline 2617 & Locutores, Comentaristas e Repórteres de Rádio e Televisão \\
\hline 2621 & Produtores Artísticos e Culturais \\
\hline 2622 & Diretores de Espetáculos e afins \\
\hline 2623 & Cenógrafos \\
\hline 2624 & Artistas visuais, Desenhistas Industriais e Conservadores-restauradores de Bens Culturais \\
\hline 2625 & Atores \\
\hline 2626 & Músicos compositores, Arranjadores, Regentes e Musicólogos \\
\hline 2627 & Músicos Intérpretes \\
\hline 2628 & Artistas da Dança \\
\hline 2629 & Designer de Interiores de Nível Superior \\
\hline 2711 & Chefes de Cozinha e afins \\
\hline
\end{tabular}




\begin{tabular}{|c|l|}
\hline $\begin{array}{c}\text { Código Brasileiro } \\
\text { e Ocupação (CBO) }\end{array}$ & \multicolumn{1}{c|}{ Ocupações da Categoria Profissionais Criativos } \\
\hline 2012 & Profissionais de Metrologia \\
2251 & Médicos Clínicos \\
2232 & Cirurgiões-Dentistas \\
2233 & Veterinários e Zootecnistas \\
2234 & Farmacêuticos \\
2235 & Enfermeiros de Nível Superior e afins \\
2236 & Profissionais da Habilitação e Reabilitação \\
2237 & Nutricionistas \\
2331 & Professores do Ensino Profissional \\
2332 & Instrutores do Ensino Profissional \\
2410 & Advogados \\
2422 & Membros do Ministério Público/Promotores Defensores Públicos \\
2515 & Psicólogos e Psicanalistas \\
2521 & Administradores de Empresas \\
2525 & Profissionais da Administração Econômico-Financeira \\
\hline
\end{tabular}

\begin{tabular}{|c|c|}
\hline $\begin{array}{l}\text { Código Brasileiro } \\
\text { e Ocupação (СBO) }\end{array}$ & Ocupações da Categoria Outros \\
\hline $\begin{array}{l}2151 \\
2152 \\
2153 \\
2311 \\
2312 \\
2313 \\
2321 \\
2341 \\
2342 \\
2343 \\
2344 \\
2345 \\
2346 \\
2347 \\
2348 \\
2349 \\
2392 \\
2394 \\
2412 \\
2423 \\
2516 \\
2522 \\
2523 \\
2524\end{array}$ & 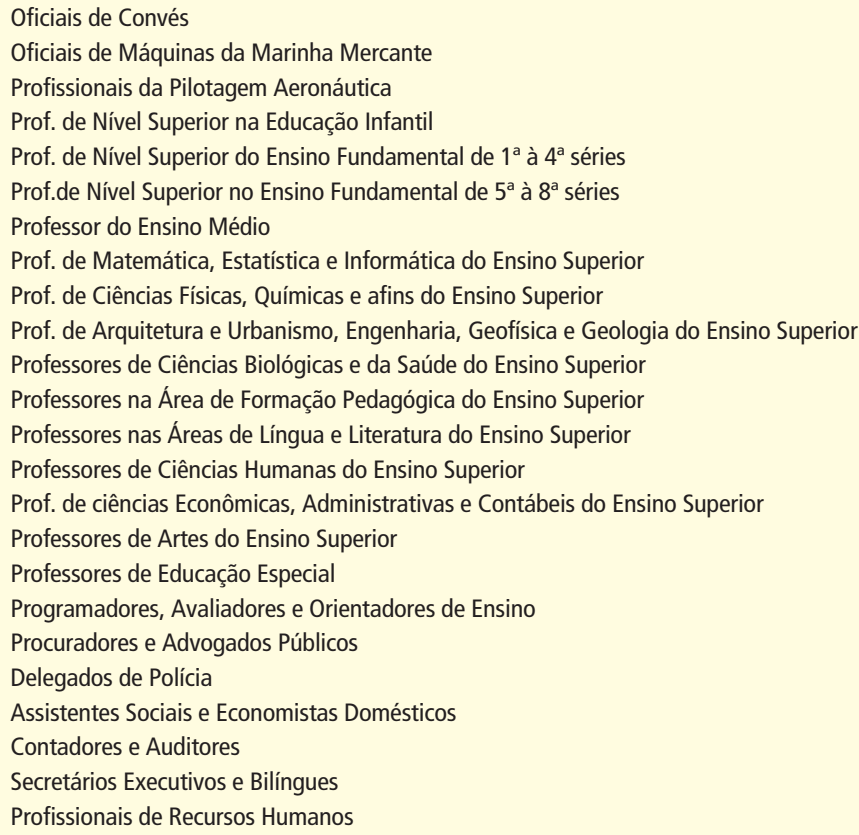 \\
\hline
\end{tabular}


O Gráfico 1 apresenta os vínculos ativos para todos os imigrantes no estado de São Paulo, segundo nacionalidade de 2002 a 2015. Nota-se, de maneira geral, que os vínculos de imigrantes no mercado de trabalho formal do estado mais do que dobraram entre 2002 e 2015, ou seja, passou-se de 22.939 para 48.023 vínculos. Entre as nacionalidades mais significativas nesses treze anos estão as latino-americanas, pois elas representaram juntas $^{23}$ pelo menos $24,1 \%$ dos vínculos em 2002 (5.522 em 22.939); 31,5\% em 2010 (8.814 em 27.942) e, finalmente, 32,5\% em 2015 (15.288 em 47.023). Além disso, cabe destacar a participação de duas nacionalidades em relação ao total, a portuguesa e a haitiana. Enquanto a primeira apresentou uma intensa diminuição de sua participação relativa e absoluta no período analisado, de $23,8 \%$ dos vínculos ativos de 2002 (5.457 em 22.939), para 9,9\% em 2015 (4.675 em 47.023); a haitiana aumenta a cada ano sua inserção no mercado de trabalho formal brasileiro, tendo passado de nenhum registro de 2002 a 2013, para 5.174 em 2014 (11,5\% em 45.100$)$ e alcançado os 7.788 vínculos em 2015 (16,6\% de 47.023).

0 Gráfico 2, por sua vez, exibe informações sobre a escolaridade dos imigrantes a partir de seus vínculos ativos de trabalho para o estado de São Paulo entre 2006 e 2015. Ressalta-se, assim, a importância do nível de instrução desses profissionais para o estudo da imigração internacional qualificada para o Brasil e de sua inserção no mercado de trabaIho nacional. Dessa forma, tem-se que a maior parte dos vínculos ativos diz respeito aos imigrantes com ensino médio completo ou com ensino superior completo, uma tendência que vem se acentuando ao longo do tempo e com o aumento no número dos vínculos de trabalho registrados pela Rais.

Nota-se, inclusive, um aumento na participação dos registros de profissionais com ensino médio completo ao longo dos anos, passando de 22,2\% em 2006 (724 em 22.597), para $24,5 \%$ em 2010 (6.056 em 25.960) e atingindo os 31,6\% em 2015 (2.351 em 47.023).

Já em relação à parcela mais escolarizada dos imigrantes inseridos no mercado de trabalho de São Paulo com nível igual ou maior do que o superior completo, é possível observar um aumento em termos absolutos (exceto para 2015) e, ao mesmo tempo, uma queda de participação relativa entre 2006 e 2015. Assim, enquanto os vínculos aumentaram mais de uma vez e meia, passando de 13.122 em 2006, para 20.876 em 2015; sua participação caiu de $58,1 \%$ (de 22.597) para 40,5\% (de 47.023). Mesmo que tenham perdido espaço na distribuição dos vínculos, os imigrantes com maiores níveis de instrução ainda representam a maior parte dos vínculos ativos registrados no mercado de trabalho formal do estado, especialmente os que apresentam ensino superior completo.

É justamente entre os imigrantes com maior escolaridade que se encontram os imigrantes trabalhadores do conhecimento, caracterizados, não apenas por seu alto nível de escolaridade, mas por um conjunto específico de ocupações, conforme o Quadro 1 (Mello, 2007). A Tabela 1 permite analisar, assim, os vínculos de ITC inseridos no mercado de trabalho formal do estado de São Paulo, segundo sexo e sua participação relativa, entre 2006 e 2015. Avalia-se que houve um crescimento de pelo menos $41,8 \%$ no total de registros para ITC de 2006 a 2015 (de 6.075 para 8.615), como já apresentado. Porém, de forma mais 


\section{Gráfico 1 - Vínculos Ativos de Imigrantes no estado de São Paulo, segundo nacionalidade 2002-2015}

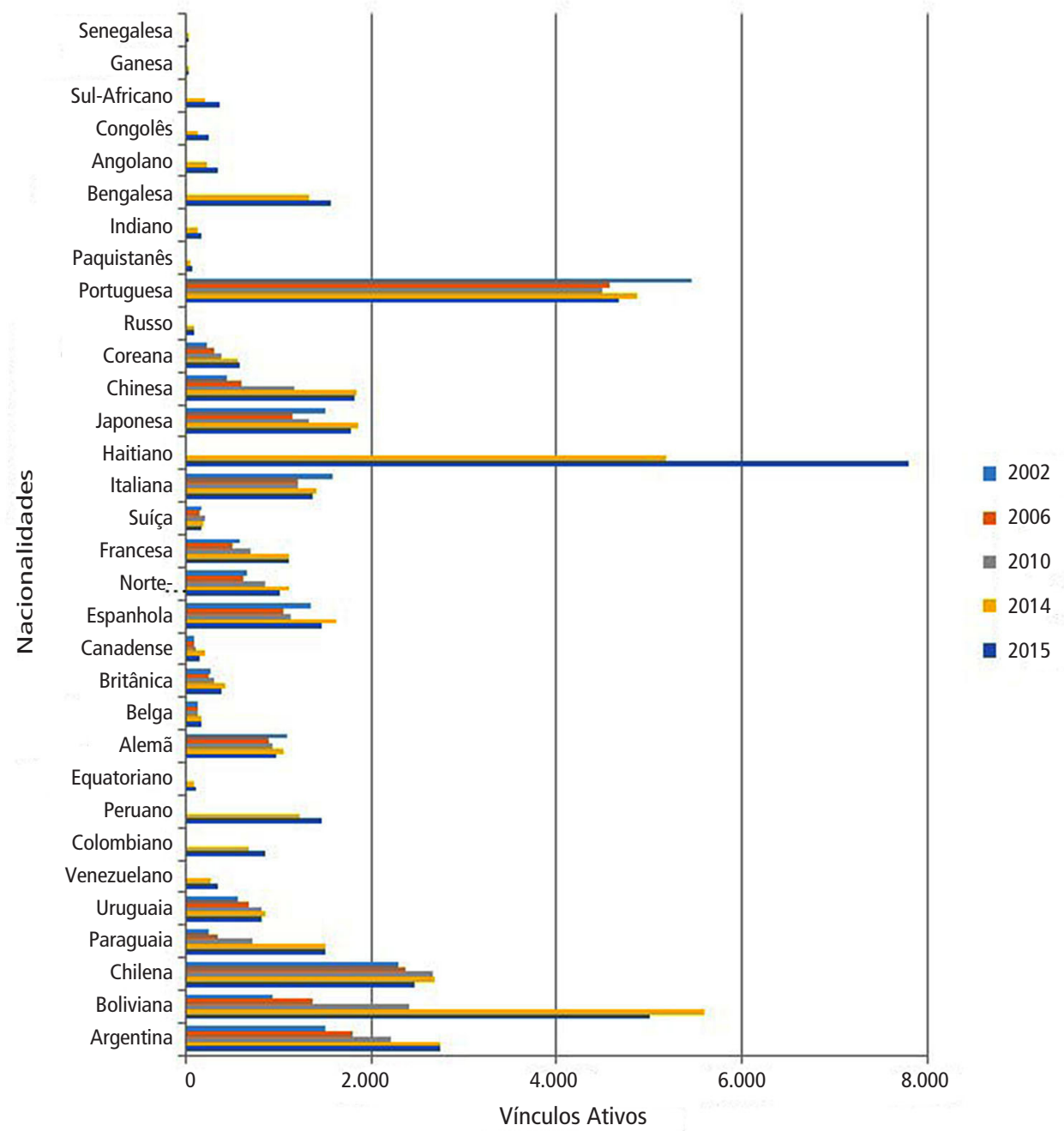

Fonte: Relação Anual de Informações Sociais 2002-2015. Observatório das Migrações em São Paulo (Fapesp-CNPq / Nepo-Unicamp). 
Gráfico 2 - Vínculos ativos de imigrantes no estado de São Paulo, segundo nível de escolaridade 2006-2015

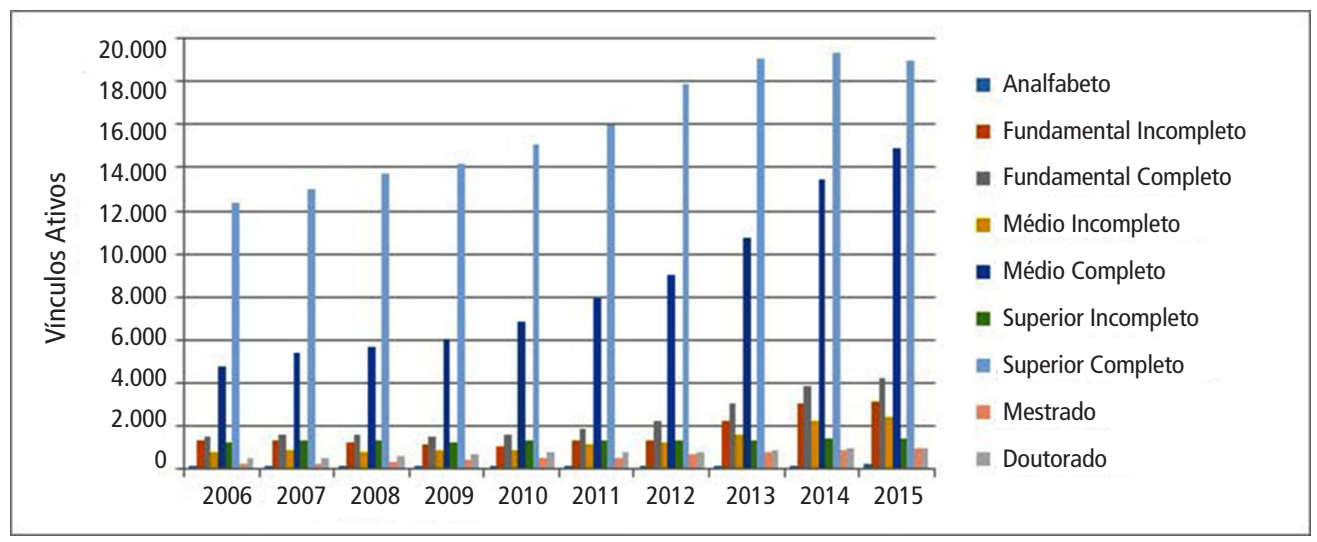

Fonte: Relação Anual de Informações Sociais, 2002-2015. Observatório das Migrações em São Paulo (Fapesp-CNPq/Nepo-Unicamp).

detalhada, observa-se que, de 2011 para 2012, houve um aumento de pelo menos $10,5 \%$ nos vínculos ativos para ITC, de 7.573 para 8.395, que foi seguido de um período de decrescimento entre 2012-2013 de -0,9\%, passando de 8.365 para 8.283 e retomando o crescimento nos anos seguintes.

Não obstante, é possível considerar que a diferença entre os vínculos de trabalho para homens e mulheres desse grupo tem se tornado mais significativa a cada ano. Observa-se, a partir disso, uma superioridade dos vínculos dos homens em comparação com os das mulheres que se intensificou no período; de modo que os registros de homens passaram de 63\% em 2006 (3.827 em 6.075), para 63,83\% em 2015 (5.499 em 8.615). Já, em termos absolutos, houve um aumento de, aproximadamente, $43,7 \%$ nos registros de trabalho para homens, de 3.827, em 2006, para 5.499 vínculos em 2015. As mulheres, por sua vez, apresentaram um acréscimo absoluto nos vínculos ativos de trabalho, entre 2006 e 2015, em média de $38,6 \%$ (de 2.248 para 3.116) e uma queda em termos relativos, visto que perderam participação no total de 2006, 37\% (2.248 em 6.075), para 2015, 36,17\% (3.116 em 8.615).

0 estudo sobre a migração internacional qualificada em São Paulo leva em consideração, também, a inserção laboral desses profissionais no mercado formal de trabalho do País. Assim, buscam-se avaliar os vínculos ativos dos ITC a partir de sua distribuição entre as três categorias de análise: o Núcleo Supercriativo, os Profissionais Criativos e o grupo Outros (Mello, 2007), entre os anos de 2006 e 2015.

Entre as funções que mais se destacam no Núcleo Supercriativo, de 2006 a 2015, estão os Analistas de sistemas computacionais; 
Tabela 1 - Vínculos Ativos de imigrantes trabalhadores do conhecimento no estado de São Paulo totais e relativos, segundo sexo, de 2006 a 2015

\begin{tabular}{l|c|c|c|c|c}
\hline Anos & Mulheres & Mulheres $-\%$ & Homens & Homens - \% & Total \\
\hline 2006 & 2.248 & 37,00 & 3.827 & 63,00 & 6.075 \\
2007 & 2.366 & 36,96 & 4.036 & 63,04 & 6.402 \\
2008 & 2.519 & 36,86 & 4.315 & 63,14 & 6.834 \\
2009 & 2.607 & 37,00 & 4.438 & 63,00 & 7.045 \\
2010 & 2.723 & 36,56 & 4.725 & 63,44 & 7.448 \\
2011 & 2.744 & 36,23 & 4.829 & 63,77 & 7.573 \\
2012 & 2.936 & 35,10 & 5.429 & 64,90 & 8.365 \\
2013 & 2.892 & 34,91 & 5.391 & 65,09 & 8.283 \\
2014 & 2.988 & 34,87 & 5.580 & 65,13 & 8.568 \\
\hline
\end{tabular}

Fonte: Relação Anual de Informações Sociais 2006-2015. Observatório das Migrações em São Paulo (Fapesp-CNPq /Nepo-Unicamp).

engenheiros eletroeletrônicos; engenheiros civis; profissionais de relações públicas, publicidade, mercado e negócios; engenheiros mecânicos e os profissionais em pesquisa e análise econômicas. Essas ocupações juntas representam, em média, $74 \%$ da categoria por ano. Os vínculos ativos para analistas de sistemas computacionais, por exemplo, exibiram um acréscimo absoluto de aproximadamente $66 \%$ entre 2006 e 2015 (de 457 para 759) e relativo, pois passaram de $28,1 \%$ do total da categoria em 2006 (457 em 1.622), para 31,1\% (759 em 2.433) em 2015.

Já, entre as ocupações relativas à categoria Profissionais Criativos, é possível ressaltar os médicos clínicos; administradores de empresas; enfermeiros de nível superior; advogados e profissionais de administração econômico-financeira, ocupações que representam juntas aproximadamente $92 \%$ do grupo Profissionais Criativos, a cada ano, entre 2006 e 2015. Cabe assinalar que os vínculos ativos relativos aos médicos clínicos são os mais expressivos entre todas as demais ocupações consideradas na análise dos imigrantes trabalhadores do conhecimento. Apesar do aumento absoluto dos registros no período, de 1.198 em 2006, para 1.542 em 2015 (ainda que com certas oscilações), a ocupação vem perdendo espaço relativo na categoria Profissionais Criativos, tendo passado de 61,2\% (1.198 em 1.959) no primeiro ano, para 55,7\% (1.542 em 2.771) no último. Ao mesmo tempo, nota-se um aumento significativo dos vínculos de trabalho de administradores de empresas, de cerca de $110 \%$ entre 2006 e 2015 (de 283 para $596)$; tendo passado de $14,5 \%$ do total da categoria em 2006 (283 em 1.959), para 23,5\% (619 em 2.685), em 2012, e terminado o período em 21,5\% (596 em 2.771). 
Finalmente, em relação à categoria $\mathrm{Ou}$ tros é possível ressaltar os vínculos de professores na área de formação pedagógica do ensino superior; nas áreas de língua e literatura do ensino superior; de nível superior no ensino fundamental ( $1^{\mathrm{a}}$ a $4^{\mathrm{a}}$ séries); de nível superior no ensino fundamental $\left(5^{\mathrm{a}}\right.$ a $8^{\mathrm{a}}$ séries); do ensino médio; de ciências humanas do ensino superior; aos programadores, avaliadores e orientadores de ensino; contadores e auditores e, por fim, aos secretários executivos e bilíngues, ocupações que, juntos, representam, em média, $78 \%$ da categoria a cada ano. Enquanto os registros de professores de formação pedagógica perderam participação no total da categoria, de 21,6\% (538 em 2.494), em 2006, para 17,4\% (592 em 3.411) em 2015, os de professores de outras áreas, como de línguas e literatura para 0 ensino superior, aumentaram de 9\% (225 em 2.494) no primeiro ano, para $14 \%$ (475 em 3.411) no último.

Finalmente, no que diz respeito ao total de cada categoria de análise dos ITC, os vínculos ativos para essa parcela mais qualificada de imigrantes apresentaram uma tendência de crescimento no período, tendo acrescido em $41,8 \%$ no geral, de 6.075 em 2006, para 8.615 em 2015. Observa-se, dessa forma, um aumento absoluto dos vínculos ativos para as três categorias, e os registros para ocupações do Núcleo Supercriativo tiveram um acréscimo de 50\% (de 1.622 para 2.433); dos Profissionais Criativos em $41,4 \%$ (de 1.959 para 2.771) e dos Outros em 36,8\% (de 2.494 para 3.280) de 2006 a 2015. Já, em termos relativos, destaca-se uma perda de participação do grupo Outros no período, visto que passou de $41,1 \%$ em 2006 (2.494 em 6.075), para 39,6\% (3.411 em 8.615) em 2015 e, ao mesmo tempo, um aumento da participação de vínculos ativos para imigrantes trabalhadores do conhecimento inseridos em ocupações da categoria Núcleo Supercriativo, que passou de 26,7\% (1.622 em 6.075), para 28,2\% (2.433 em 8.615) em 2015. A categoria de Profissionais Criativos, por sua vez, não apresentou grandes mudanças em sua participação no total dos vínculos ativos de imigrantes profissionais do conhecimento, mantendo-se com $32,2 \%$ dos registros totais em 2006 (1.959 em 6.075) e em 2015 (2.771 em 8.615).

\section{Os espaços da migração dos imigrantes trabalhadores do conhecimento no estado de São Paulo no início do século XXI}

Tendo em vista a diversidade dos vínculos ativos de imigrantes trabalhadores do conhecimento no estado de São Paulo analisados, pretende-se avaliar a distribuição espacial desses profissionais que conseguiram se inserir no mercado formal de trabalho brasileiro em anos recentes de forma a estabelecer um panorama da migração internacional qualificada para 0 País e para o estado no contexto atual. Leva-se em consideração, sobretudo, a distribuição especial desses imigrantes entre os diferentes municípios de São Paulo (com base nas maIhas municipais disponibilizadas pelo IBGE), de forma a estabelecer uma análise que, como apontado por Baeninger (2014a), envolva as dimensões espaciais do fenômeno e viabilize 0 estudo das mudanças ocorridas nos espaços da 
migração nas primeiras décadas do século XXI. Busca-se, desse modo, apreender os pontos de aproximação e distanciamento em relação à presença de trabalhadores do conhecimento imigrantes e nacionais em determinados espaços e, ao mesmo tempo, as transformações observadas ao longo do período considerado.

0 Mapa 1 apresenta a distribuição espacial dos vínculos ativos dos imigrantes trabaIhadores do conhecimento entre os diferentes municípios do estado de São Paulo para 2006, 2010, 2014 e 2015 e o Mapa 2 refere-se aos registros de trabalhadores do conhecimento nacionais para 2015.

Com relação aos vínculos de ITC, avalia-se, inicialmente, uma concentração significativa no município de São Paulo, que se intensifica ao redor da capital ao longo dos anos. Ademais, é possível discernir os vínculos relativos a São Paulo no último nível da legenda para cada ano, visto que a cidade conta com o maior número de registros referentes a esse estrato populacional. Portanto, em 2006 eram 3.539 vínculos; em 2010, 4.511; em 2014,

\section{Mapa 1 - Distribuição espacial dos vínculos ativos de imigrantes trabalhadores do conhecimento segundo municípios do estado de São Paulo para 2006, 2010 e 2014, respectivamente}

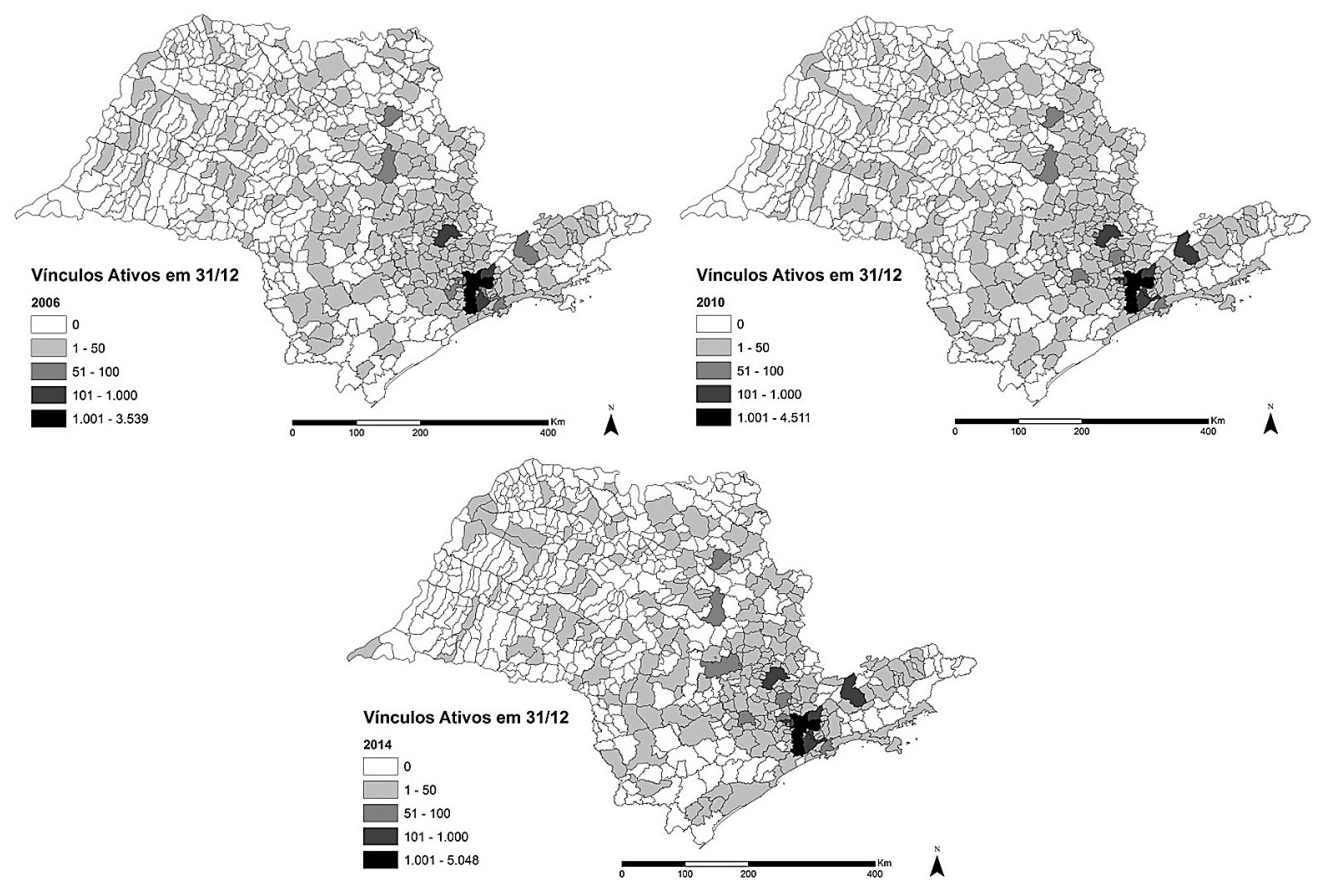

Fonte: Malhas Digitais (FIBGE, 2010) e Relação Anual de Informações Sociais, 2006, 2010 e 2014. Observatório das Migrações em São Paulo (Fapesp-CNPq /Nepo-Unicamp). 
5.046 e, em 2015, com uma leve queda em relação ao ano anterior, foram 5.035 .

No que diz respeito ao interior paulista, ressalta-se, durante os 4 anos, um aumento no número de municípios que contam com vínculos ativos para imigrantes trabalhadores do conhecimento, ainda que essa diversificação seja limitada e tenda a variar ao longo do tempo. No geral, para além da região metropolitana de São Paulo (RMSP), que será tratada mais adiante, observa-se um aumento dos registros em alguns municípios específicos, como São José dos Campos (96 em 2006 e 178 em 2015); Campinas (317 em 2006 e 494 em 2015); Piracicaba (40 em 2006, 62 em 2014 e 58 em 2016); São Carlos (53 em 2006 e 99 em 2015) e, finalmente, Ribeirão Preto (71 em 2006 e 101 em 2015).

Logo, distingue-se um aumento de $41,8 \%$ entre 2006 e 2015 (de 6.075 para 8.615) nos vínculos ativos de ITC no estado de São Paulo; e o período de crescimento mais intenso se deu entre 2006 e 2010, com 22,6\% (de 6.075 para 7.448).

A partir do que foi discutido, é interessante pensar possíveis semelhanças entre os espaços de inserção dessa mão de obra altamente especializada imigrante e nacional nos diferentes espaços de alocação do capital e da força de trabalho no estado. Busca-se, portanto, estabelecer uma comparação entre a distribuição espacial dos vínculos ativos de imigrantes e de nacionais trabalhadores do conhecimento nos diferentes municípios do estado. 0 Mapa 2 apresenta, para o ano de 2015, as informações sobre os registros dos imigrantes e dos nacionais, seguidamente. Nota-se, em primeiro lugar, a disparidade no volume de vínculos para os dois estratos sociais, visto que a quantidade de nacionais altamente qualificados, como esperado, é expressivamente superior à de imigrantes trabalhadores do conhecimento, por isso a diferença nas legendas. Não obstante, para além da capital São Paulo, grande centro de concentração de trabalhadores do conhecimento no País, sejam eles nacionais ou não, cabe apontar uma sobreposição espacial dos municípios que mais se destacam em relação aos vínculos de trabalho de nacionais e os de presença imigrante. Entre eles, ressaltam-se os já citados, São José dos Campos, Campinas, Piracicaba, São Carlos e Ribeirão Preto, mas também os da RMSP, como Guarulhos, São Bernardo do Campo, Osasco e Santo André.

É interessante ponderar, a partir disso, que as dinâmicas migratórias observadas do ponto de vista da migração interna por Baeninger (2005, p. 93), em meio às mudanças econômico-espaciais do final do século $X X$, já apontavam para a "dispersão populacional no estado" e para um "rearranjo das formas de distribuição espacial da população no âmbito da região". Ressalta-se, ainda, a importância de polos regionais como Campinas, São José dos Campinas e Ribeirão Preto no processo de "espraiamento populacional" que antes envolvia a migração interna (ibid., p. 94) e, no século XXI, destacam-se, também, pela presença da migração internacional qualificada.

Tendo em vista o cenário encontrado, é importante pensar os fluxos de ITC no estado de São Paulo a partir de suas especificidades, especialmente, no que diz respeito aos diferentes espaços de inserção da migração internacional no âmbito local, nacional e global e à relação com a dinâmica produtiva e financeira internacional. 


\section{Mapa 2 - Distribuição espacial dos vínculos ativos de trabalhadores do conhecimento imigrantes e nacionais segundo municípios do estado de São Paulo, respectivamente, para 2015}

Imigrantes Trabalhadores do Conhecimento

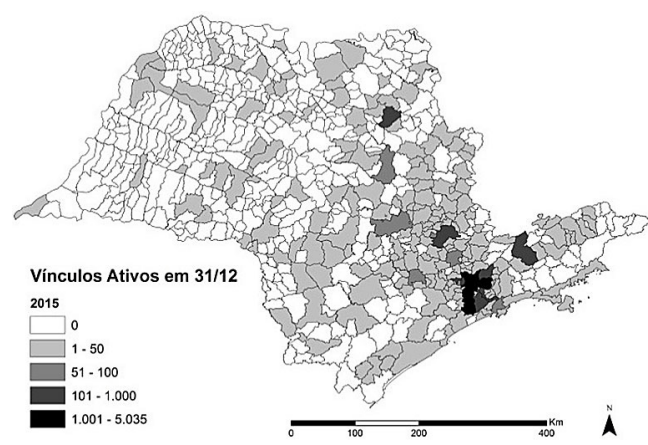

Nacionais Trabalhadores do Conhecimento

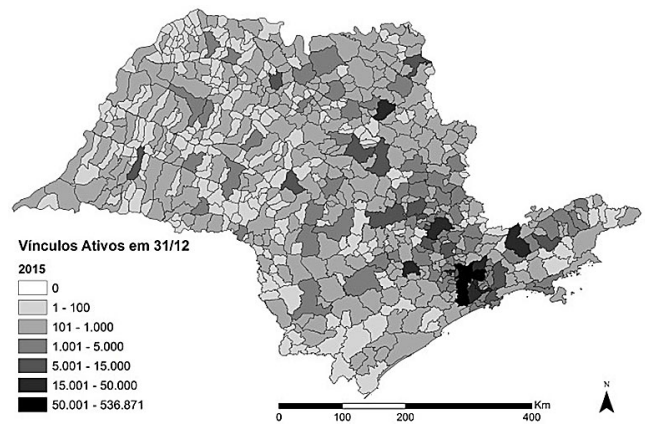

Fonte: Malhas Digitais (FIBGE, 2010) e Relação Anual de Informações Sociais, 2015. Observatório das Migrações em São Paulo (Fapesp-CNPq/Nepo-Unicamp).

Como apresenta Baeninger (2014b, p. 5) a respeito da migração interna, mas que pode ser pensado, também, para a migração internacional, "a análise dos movimentos migratórios nos anos 2000 reforça a tendência de configuração de novos espaços da migração, com a necessidade de diferentes olhares para as escalas onde esses fluxos se processam, seus sentidos e repercussões em diferentes níveis (Vainer, 2002; Brandão, 2007)". Seria necessário, portanto, refletir as migrações do ponto de vista de uma reestruturação urbana, de modo que essas mudanças fossem compreendidas a partir dos diferentes processos em curso, entre eles a "redistribuição espacial da população" a "urbanização" e as "migrações" (Baeninger, 2014b, p. 6). Nesse sentido,
[...] 0 processo de reestruturação produtiva em âmbito internacional tem contribuído, em nível nacional, regional e local, para a configuração de espaços urbanos selecionados (Sassen, 1988). [...] Modificaram-se as formas e os processos urbanos até então vigentes nas cidades; intensificou-se a velocidade das transformações tecnológicas; as cidades pequenas e de porte médio passaram a constituir uma importante fatia do dinamismo regional; mudaram a direção e o sentido dos fluxos migratórios nacionais e internacionais. (Ibid.)

Deve-se levar em consideração, também, que "a reestruturação urbana se articula à reorganização econômica mundial, refletindo os impactos territoriais do processo de reestruturação produtiva" (ibid., pp. 6-7). Assim, 
quanto mais as regiões vão inserindo seus segmentos na economia internacional, mais propensas se tornam essas áreas para experimentarem a rotatividade de suas populações, com a fluidez da mão de obra nos setores dessa produção. Oscilará tanto na origem quanto no destino; haverá mão de obra excedente vinculada a esse processo global de reestruturação da produção e de circulação de capital. (Ibid., p. 19)

A partir dessa perspectiva, seria possível apreender as mudanças notadas na distribuição espacial dos ITC entre os diferentes municípios do estado de São Paulo, 645 no total, tendo em vista sua inserção no mercado de trabalho formal com base nos registros administrativos disponibilizados pela Rais.

A Tabela 2 apresenta, assim, os vínculos ativos de Imigrantes Trabalhadores do Conhecimento (ITC) na capital do estado, São Paulo, na região metropolitana (RMSP) e nos municípios do interior paulista; assim como suas respectivas participações no total do estado, entre 2006 e 2015. Ressalta-se, nesse sentido, que a RMSP envolve 39 municípios, entre eles a capital, São Paulo, além de Arujá, Barueri, Biritiba-Mirim, Caieiras, Cajamar, Carapicuíba, Cotia, Diadema, Embu das Artes, Embu-Guaçu, Ferraz de Vasconcelos, Francisco Morato, Franco da Rocha, Guararema, Guarulhos, Itapevi, Itapecerica da Serra, Itaquaquecetuba, Jandira, Juquitiba, Mairiporã, Mauá, Mogi das Cruzes, Osasco, Pirapora do Bom Jesus, Poá, Ribeirão Pires, Rio Grande da Serra, Salesópolis, Santa Isabel, Santana de Parnaíba, Santo André, São Bernardo do Campo, São Caetano do Sul, São Lourenço da Serra, Suzano, Taboão da Serra e Vargem Grande Paulista, enquanto o interior engloba as demais 606 cidades do estado.
Primeiramente, observa-se que, para todas as espacialidades consideradas, houve um aumento no número de vínculos ativos para o estrato social considerado; o interior do estado apresentou aproximadamente 53,8\% (de 1.459 para 2.242), enquanto o município de São Paulo, 42,3\% (de 3.539 para 5.035) e, por fim, a RMSP, 38,1\% (de 4.616 para 6.373) de aumento nos vínculos entre 2006 e 2015. Não obstante, cabe destacar que a tendência de crescimento no número de registros administrativos para imigrantes trabalhadores do conhecimento exibiu oscilações na capital e na RMSP, ao passo que no interior se manteve de forma progressiva ao longo dos 10 anos analisados. No que diz respeito a São Paulo, nota-se um aumento dos registros até 2012 (de 3.539 em 2006, para 5.068 em 2012), ano em que alcança seu número mais elevado de vínculos de trabalho para os ITC, seguido de uma oscilação de 4.909 em 2013, para 5.048, em 2014 e alcançando os 5.035, em 2015. Na RMSP, por sua vez, é possível aferir um crescimento do número de vínculos até 2012 (de 4.616, em 2006, para 6.365 em 2012), seguido de um período de variações nos registros, de modo que, em 2013, foram 6.236, em 2014, 6.406 e, finalmente, em 2015, 6.373 vínculos ativos para ITC.

A Tabela 2 apresenta, ainda, a participação dos vínculos ativos de ITC do município de São Paulo em relação ao total no estado entre 2006 e 2015. Observa-se, a seguir, uma baixa variação na participação relativa dos registros administrativos de trabalho dos ITC de São Paulo no total, visto que iniciou o período analisado com 58,26\% em 2006 (3.539 em 6.075), atingiu seu ponto mais elevado no ano de 2009 , com $60,6 \%$ dos vínculos (4.269 
em 7.045), e culminou em 58,45\% (5.035 em 8.615) em 2015.

Ademais, a Tabela 2 exibe a distribuição espacial dos vínculos ativos de ITC no estado tendo em vista uma divisão analítica entre os municípios da RMSP e do interior. Nota-se, de forma geral, que a maior parte dos vínculos ativos de imigrantes trabalhadores do conhecimento encontra-se na RMSP, ainda que seja possível observar uma variação ao longo do tempo. Essa oscilação resulta em uma queda na participação relativa dos registros na região metropolitana em relação ao total de $75,98 \%$ (4.616 em 6.075) em 2006 para 73,98\%
(6.373 em 8.615) em 2015. Em contraposição, há um aumento da participação relativa dos vínculos ativos dos ITC no interior paulista, a qual passou de 24,02\% (1.459 em 6.075) em 2006, para 26,02\% (2.242 em 8.615) em 2015. Nesse sentido, pode-se pensar que, apesar de a RMSP, sobretudo São Paulo, representar a maior parte dos vínculos ativos para imigrantes trabalhadores do conhecimento no estado, os municípios do interior paulista ganharam espaço entre 2006 e 2015, aumentando a inserção no mercado formal de trabalho de uma mão de obra internacional altamente qualificada e escolarizada.

Tabela 2 - Vínculos ativos de Imigrantes Trabalhadores do Conhecimento (ITC) no município de São Paulo (SP), na Região Metropolitana de São Paulo (RMSP) e no Interior do estado de São Paulo e respectivas participações no total de ITC do estado, 2006-2015

\begin{tabular}{l|c|c|c|c|c|c|c}
\hline Anos & $\begin{array}{c}\text { Municipio } \\
\text { de São } \\
\text { Paulo }\end{array}$ & $\begin{array}{c}\text { Participação } \\
\text { do Munic. de } \\
\text { SP no Total } \\
\text { do estado }\end{array}$ & $\begin{array}{c}\text { Total de ITC } \\
\text { na RMSP }\end{array}$ & $\begin{array}{c}\text { Participação } \\
\text { da RMSP } \\
\text { no Total do } \\
\text { estado }\end{array}$ & $\begin{array}{c}\text { Total de ITC } \\
\text { no Interior }\end{array}$ & $\begin{array}{c}\text { Participação } \\
\text { do Interior } \\
\text { no Total do } \\
\text { estado }\end{array}$ & $\begin{array}{c}\text { Total de ITC } \\
\text { no estado } \\
\text { de SP }\end{array}$ \\
\hline 2006 & 3.539 & 58,26 & 4.616 & 75,98 & 1.459 & 24,02 & 6.075 \\
2007 & 3.736 & 58,36 & 4.835 & 75,52 & 1.567 & 24,48 & 6.402 \\
2008 & 4.117 & 60,24 & 5.262 & 77,00 & 1.572 & 23,00 & 6.834 \\
2009 & 4.269 & 60,60 & 5.411 & 76,81 & 1.634 & 23,19 & 7.045 \\
2010 & 4.511 & 60,57 & 5.754 & 77,26 & 1.694 & 22,74 & 7.448 \\
2011 & 4.518 & 59,66 & 5.746 & 75,87 & 1.827 & 24,13 & 7.573 \\
2012 & 5.068 & 60,59 & 6.365 & 76,09 & 2.000 & 23,91 & 8.365 \\
2013 & 4.909 & 59,27 & 6.236 & 75,29 & 2.047 & 24,71 & 8.283 \\
2014 & 5.048 & 58,92 & 6.406 & 74,77 & 2.162 & 25,23 & 8.568 \\
2015 & 5.035 & 58,45 & 6.373 & 73,98 & 2.242 & 26,02 & 8.615 \\
\hline
\end{tabular}

Fonte: Relação Anual de Informações Sociais 2006-2015. Observatório das Migrações em São Paulo (Fapesp-CNPq /NepoUnicamp). 
A partir disso, busca-se apreender como se dá essa distribuição dos vínculos de trabalho para os ITC entre os diferentes municípios do estado, segundo interior e RMSP, como apresentado nos Mapas 3 e 4, respectivamente, 2006 e 2015. Porém, é necessário ter em vista que a escala de cores cinza diz respeito aos municípios do interior paulista, enquanto a escala de cores azul, amarela e vermelha trata da RMSP. Essa diferença permite uma análise mais detalhada da mudança no número de vínculos ativos dos imigrantes para alguns municípios específicos ao longo do tempo, especialmente, na região metropolitana.

Observa-se, nesse sentido, que em 2006, a RMSP representava 75,98\% dos vínculos ativos de ITC em todo o estado, ou seja, 4.616 dos 6.075, enquanto o interior contava com 24,02\%, 1.459 em 6.075. Assim, é possível avaliar que a maior parte dos registros dos imigrantes trabalhadores do conhecimento no estado encontrava-se, principalmente, em São Paulo (3.539 em 4.616 vínculos), como apresentado na Tabela 2. Além da capital, destacam-se, São Bernardo do Campo, com 152 registros, e Guarulhos, com 131; Santo André, com 98, Barueri, com 98, Osasco, com 95, Cotia, com 54, e São Caetano do Sul, com 53. Já no interior do estado se sobressaem, em 2006, Campinas, o segundo município em vínculos ativos de ITC no estado, com 317; além de São José dos Campos, com 96, Santos, com 90, Ribeirão Preto, com 71 e São Carlos, com 53.

0 Mapa 4, por sua vez, apresenta os vínculos ativos para imigrantes trabalhadores do conhecimento segundo RMSP e interior do estado de São Paulo em 2015. Nesse ano, a RMSP apresentou um aumento absoluto, mas uma participação relativa inferior à de 2006, com aproximadamente, $73,98 \%$ dos registros totais desse grupo de profissionais no estado, ou 6.373 em 8.615. Desse montante, grande parte pode ser atribuída ao município de São Paulo, com 5.035 dos 6.373 vínculos ativos de ITC no ano de 2015. Outras cidades que merecem ser destacadas são: Santo André, com 256 registros, Barueri, com 172, São Bernardo do Campo, com 161, Guarulhos, com 125, e Osasco, com 102; além de Carapicuíba, com 61 e São Caetano do Sul, com 54 vínculos ativos. Enquanto isso, no Interior paulista, Campinas manteve o posto de segunda cidade com maior número de registros administrativos para os ITC em 2015, com 494; enquanto São José dos Campos, com 178, Ribeirão Preto, com 101, São Carlos, com 99 e Santos, com 93, mantiveram-se entre os municípios mais significativos. Não obstante, há um aumento dos vínculos de imigrantes em outras cidades do interior paulista, entre elas: Jundiaí, que passou de $36 \mathrm{em}$ 2006, para 84 registros em 2015, Sorocaba, com 45 em 2006 e 78 em 2015, Piracicaba, com 40 em 2006 e 58 em 2015, e Hortolândia, com 35 em 2006, para 63 em 2015.

A partir disso, nota-se, comparativamente, uma semelhança nos municípios de maior presença dos ITC em 2006 e depois em 2015 tanto na RMSP, como no interior paulista, visto que a maior parte apresentou um aumento absoluto nos registros. Porém, cabe destacar, na análise desses dados, um acréscimo importante nos vínculos ativos de outras cidades do interior do estado de São Paulo, as quais têm exibido uma tendência de crescimento nos registros administrativos de ITC inseridos no mercado de trabalho formal no período, ainda que com algumas oscilações. 
Mapas 3 e 4 - Distribuição espacial dos vínculos ativos de imigrantes trabalhadores do conhecimento por municípios do estado de São Paulo, segundo Região Metropolitana de São Paulo (RMSP) e Interior, respectivamente, para 2006 e 2015
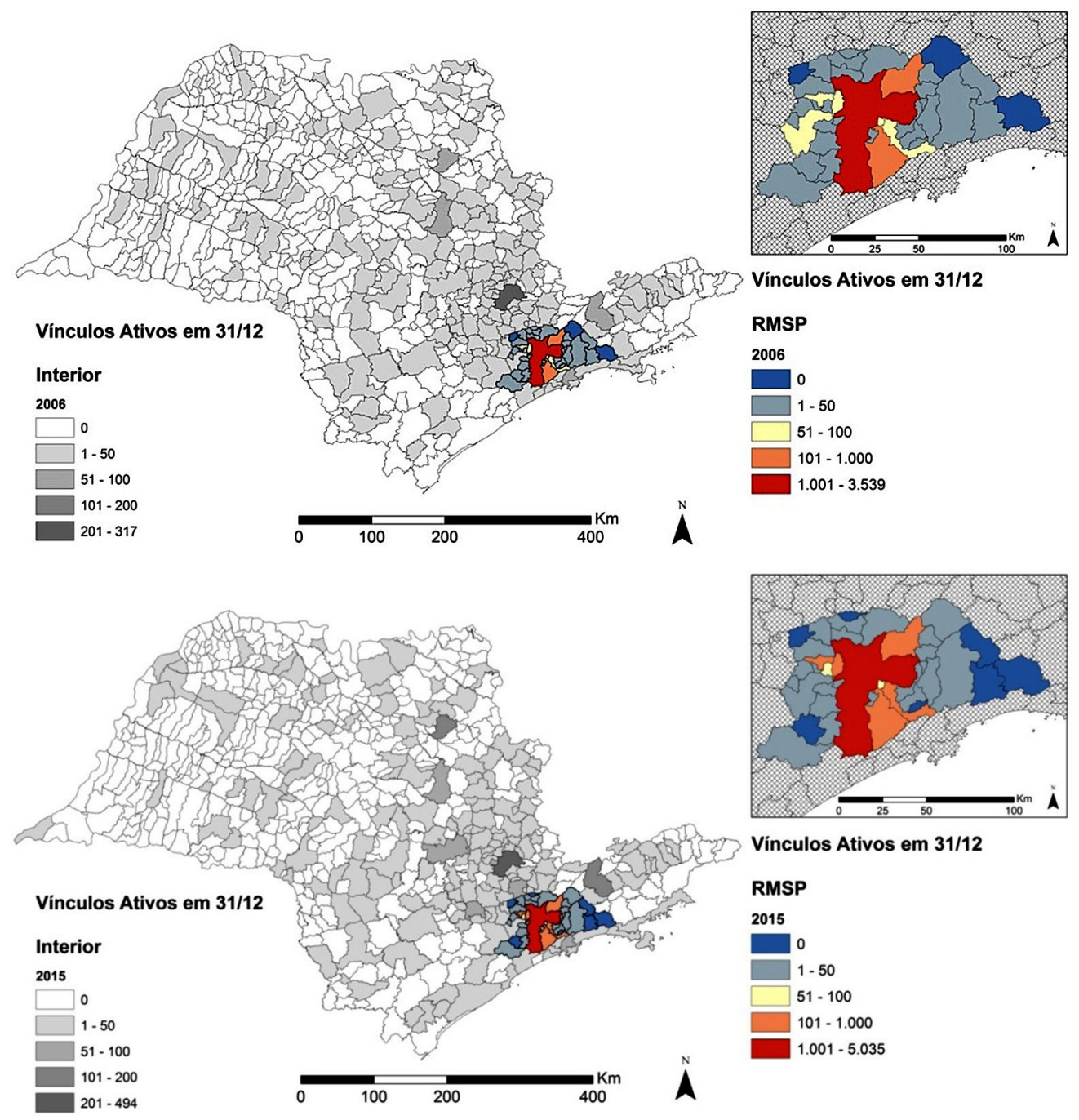

Fonte: Malhas Digitais (FIBGE, 2010) e Relação Anual de Informações Sociais, 2006- 2015. Observatório das Migrações em São Paulo (Fapesp-CNPq /Nepo-Unicamp). 


\section{Considerações finais}

Com base no aporte teórico da migração internacional qualificada e da circulação de cérebros e nos dados sobre vínculos ativos de trabalho no mercado formal, fornecidos pela Rais, é possível apreender algumas considerações gerais sobre os fluxos migratórios de profissionais altamente qualificados para o Brasil e para o estado de São Paulo. A primeira diz respeito à crescente formalização das atividades realizadas pelos imigrantes e imigrantes trabalhadores do conhecimento no mercado de trabalho do estado, o que estaria acompanhado de uma melhora constante nas informações disponibilizadas na Rais.

A segunda trata do aumento no número nos vínculos de trabalho para profissionais altamente qualificados, tendo em vista seu nível de escolaridade e sua inserção em ocupações consideradas estratégicas em uma sociedade que valoriza, cada vez mais, o conhecimento (Castells, 1996).

Por fim, o presente trabalho dá elementos para se pensar a inserção dos imigrantes trabalhadores do conhecimento nos diferentes espaços da migração do estado de São Paulo, enquanto parte de uma dinâmica migratória transnacional de mão de obra qualificada. Sobretudo, em locais com potencial científico e econômico de absorção desses profissionais, onde teriam, supostamente, melhores condições de alocação laboral, política, cultural e econômica. Destaca-se, dessa forma, a significativa presença de trabalhadores qualificados na capital, São Paulo, e em seu entorno, na região metropolitana, sem desconsiderar, porém, sua crescente dispersão pelo interior paulista nos primeiros momentos do século XXI.

\section{Jóice de Oliveira Santos Domeniconi}

Universidade Estadual de Campinas, Instituto de Filosofia e Ciências Humanas. Campinas, SP/Brasil. joicedomeniconi@outlook.com

\section{Rosana Baeninger}

Universidade Estadual de Campinas, Departamento de Demografia, Núcleo de Estudos de População Elza Berquó. Campinas, SP/Brasil.

baeninger@nepo.unicamp.br 


\section{Notas}

(1) Esse conjunto de políticas contemplava dez medidas: disciplina fiscal; realocação das prioridades dos gastos públicos; reforma tributária; liberalização da taxa de juros; manutenção da taxa de juros ema níveis competitivos; liberalização do comércio interno; liberalização dos fluxos de investimento estrangeiro direto; privatizações; desregulamentação dos capitais estrangeiros e, por fim, consolidação dos direitos de propriedade (Willianson apud CID, 2003).

(2) No original: "pool of potential migrants".

(3) No original: "the generalization of market relations has historically had a dissolution effect on traditional work structures and promoted the formation of labor migrations".

(4) No original: "putting capital in other regions of the world necessarily involves staff migration. Transnational corporations favor meeting the labor force with capital making the movement of labor towards capital or transferring capital to areas with labor force surplus".

(5) No original: "not only from its lesser volume and social visibility, when compared with other migratory movements but also from its direct link with movements of capital and the temporary strategies it frequently employs".

(6) A formulação desse aparato conceitual-analítico sobre a migração internacional qualificada contou com a colaboração de diferentes organizações internacionais, entre elas, a OCDE, a Eurostat, a Unesco e a OIT (OCDE, 1995, p. 2).

(7) No original: "Human Resources devoted to Science and Technology (HRST)" (OCDE, 1995, p. 2).

(8) No original: "successfully completed education at the third level in an S\&T field of study (...) employed in a S\&T occupation where the above qualifications are normally required" (OCDE, 1995, p. 16).

(9) É importante observar que, segundo o "Manual Canberra", entende-se ciência como o estudo de diferentes áreas do conhecimento como "matemática, física e economia", enquanto tecnologia, envolveria a aplicação de conhecimentos que exijam o uso de "instrumentos e técnicas para atingir determinados objetivos" (OCDE, 1995, p. 16; tradução livre).

(10) No original: "special skilled labour force" (OCDE, 1995, p. 8).

(11) No original: "formal qualification and corresponds to an existing and widely used international classification, the International Standard Classification of Education (ISCED)" (Auriol e Sexton, 2001, p. 15).

(12) No original: "knowledge workers are one of the most important elements, which show country's ability to compete in the global market. Moreover, they could be defined as the driving axle of 'brain circulation'" (Daugeliene e Marcinkeviciene, 2009, p. 50).

(13) No original: "convert knowledge, intellect, wisdom and ideas into tangible innovative product or service".

(14) No original: "today's globalized economy requires economies to nurture pools of well-educated workers who are able to adapt rapidly to their changing environment".. 
(15) No original: "La diversidad de migrantes calificados hoy día [...] está vinculada a la diversidad de los circuitos de migración y "ecosistemas" que favorecen la movilidad internacional y el éxito profesional. Los circuitos en los que este sector se desenvuelve están constituidos por [...] espacios que cuentan con sus propios mecanismos, políticas y procesos que facilitan la movilidad de la mano de obra especializada que requieren contratar, lo que incluye formas de contratación, remuneraciones atractivas, beneficios de seguros de salud y muchas veces otras prestaciones especiales".

(16) No original: "Las categorías de la migración calificada se han complejizado y diversificado en las últimas décadas, abarcando desde la clásica migración laboral de trabajadores calificados, a partir de su experiencia laboral, a los profesionales independientes con título universitario de las áreas de administración de empresas, finanzas, negocios y afines, los gerentes, ejecutivos o funcionarios especializados de empresas multinacionales que se trasladan dentro de su misma empresa, el sector altamente calificado en ciencia, tecnología, ingeniería y matemáticas (...) incluyendo el área de tecnología de la información, y los estudiantes de educación superior que salen a cursar estudios en el exterior".

(17) No original: "al crecimiento económico, ya que se trata de personas que tienen un gran potencial de generar valor económico, científico, tecnológico y cultural debido a sus habilidades y conocimientos, por lo que se les conoce como 'migrantes de alto valor"'.

(18) Por ser uma publicação digital, e-book, será utilizada a posição da citação no texto.

(19) No original: "add economic value through their creativity".

(20) "Essa classificação descreve e ordena as ocupações dentro de uma estrutura hierarquizada que permite agregar as informações referentes à força de trabalho" (Palermo, Oliveira e Lopes, 2015, p. 27).

(21) Mais informações sobre os dados disponibilizados pela Rais e suas descrições em: ftp://ftp.mtps. gov.br/pdet/microdados/RAIS/Layouts/v\%EDnculos/ . Acesso em: 30 nov 2016.

(22) Foram selecionados trabalhadores com ensino superior completo, mestrado e doutorado.

(23) É possível avaliar de forma discriminada apenas as nacionalidades argentina, boliviana, chilena, paraguaia, uruguaia, venezuelana, colombiana, peruana e equatoriana.

\section{Referências}

AURIOL, L. e SEXTON, J. (2001). Human Resources in Science and Technology: Measurement issues and international mobility. In: International mobility of the highly skilled. Paris, OCDE Publication Service, pp. 13-38.

BAENINGER, R. (2005). São Paulo e suas migrações no final do século 20. São Paulo em Perspectiva, v. 19, n. 3, pp. $84-96$

(2014a). Migrações internacionais no século 21: desafios para uma agenda de pesquisa. In: VI CONGRESO DE LA ASOCIACIÓN LATINO AMERICANA DE POBLACIÓN. Atas..., Lima-Peru. 
BAENINGER, R. (2014b). Rotatividade Mmgratória no Brasil: entre o local e o global. In: VI CONGRESO DE LA ASOCIACIÓN LATINO AMERICANA DE POBLACIÓN. Atas... Lima- Peru.

BRANDÃO, C. A. (2007). "Epílogo". In: Território e desenvolvimento: as múltiplas escalas entre o local e o global. Campinas, SP, Editora da Unicamp.

BRAUDEL, F. (1987). “O tempo do mundo”. In: A dinâmica do capitalismo. Rio de Janeiro, Rocco.

BRITO, F. (1995). "Os povos em movimento: as migrações internacionais no desenvolvimento do capitalismo". In: PATARRA, N. (coord.). Emigração e imigração Internacionais no Brasil contemporâneo. São Paulo, FNUAP.

CASTELLS, M. (1996). "The Rise of Network Society". In: The Information Age: Economy, Society, and Culture. Oxford, Blackwell Publishers.

CBO - CLASSIFICAÇÃO BRASILEIRA DE OCUPAÇÕES (2010). Classificação Brasileira de Ocupações. Brasília, Ministério do Trabalho e Emprego, Secretaria de Políticas Públicas de Emprego, 3a ed. v. 3.

CHESNAIS, F. (1996). A mundialização do capital. São Paulo, Xamã.

CID - CENTER FOR INTERNATIONAL DEVELOPMENT AT HARVARD UNIVERSITY (2003). Washington Consensus. Disponível em: http://www.cid.harvard.edu/cidtrade/issues/washington.html. Acesso em: 17 maio 2016.

COMITÊ DE ESTATÍSTICAS SOCIAIS. Relação Anual de Informações Sociais. Disponível em: http://ces. ibge.gov.br/base-de-dados/metadados/mte/relacao-anual-de-informacoes-sociais-rais.html. Acesso em: 30 nov 2016.

DAUGELIENE, R. e MARCINKEVICIENE, R. (2009). Brain Circulation: Theoretical Considerations. Inzinerine Ekonomika-Engineering Economics, v. 3, pp. 49-57.

FLORIDA, R. (2014). The rise of the creative class: and how it's transforming work, leisure, community \& everyday life. Nova York, Basic Books (e-book).

HAGIU, A. (2010). The influence of transnational corporations on labor force migration in Romania and in the European Union in the context of global crisis. Anale. Seria Ştiinţe Economice. Timişoara, v. 16, pp. 344-351.

IBGE - Instituto Brasileiro de Geografia e Estatística. Relação Anual de Informações Sociais - Comitê de Estatísticas Sociais. Disponível em: http://ces.ibge.gov.br/base-de-dados/metadados/mte/ relacao-anual-de-informacoes-sociais-rais.html. Acesso em: 30 nov 2016.

MARTINE, G. (2005). A globalização inacabada - As migrações internacionais e pobreza no século 21. São Paulo em Perspectiva, v. 19, n. 3.

MELLO, L. F. (2007). Trabalhadores do conhecimento e qualidade do lugar em Campinas - SP. Tese de Doutorado. Campinas-SP, Universidade Estadual de Campinas.

OCDE - ORGANIZAÇÃO PARA COOPERAÇÃO E DESENVOLVIMENTO ECONÔMICO (1995). The measurement of scientific and technological activities: Manual on the measurement of human resources devoted to S\&T "Canberra Manual". Paris, Publication Service.

OIM - ORGANIZAÇÃO INTERNACIONAL PARA MIGRAÇÕES. Migración calificada y desarrollo: Desafíos para América del Sur. Cuadernos Migratórios, n.17. Buenos Aires, Organización Internacional para las Migraciones. 
PALERMO, G.; OLIVEIRA, A. T. e LOPES, J. (2015). Conceitos e notas metodológicas - CGIg/CNIg, RAIS, Censo Demográfico (IBGE). I A inserção dos imigrantes no mercado de trabalho brasileiro, v. 1, n. 2. Brasília, OBMigra, Ed. Especial.

PATARRA, N. L. (2005). Migrações internacionais de e para o Brasil contemporâneo - volumes, fluxos, significados e políticas. São Paulo em Perspectiva, v. 19, n. 3, pp. 23-33.

PEIXOTO, J. (2001). The International Mobility of Highly Skilled Workers in Transnational Corporations: The Macro and Micro Factors of the Organizational Migration of Cadres. International Migration Review, v. 35, n. 4, pp. 1030-1053.

PELLEGRINO, A. (2003). La migración internacional en América Latina y el Caribe: tendencias y perfiles de los migrantes. Serie Población y Desarrollo. Santiago de Chile, Cepal, Naciones Unidas, 35.

PEREIRA, G. G. (2015). Entre o partir e o chegar: os trabalhadores rurais migrantes em Matão/SP. Dissertação de Mestrado. Campinas, Universidade Estadual de Campinas.

SASSEN, S. (1988). The mobility of labor and capital: a study in international investment and labor flow. Cambridge, Cambridge University Press.

SAXENIAN, A. (2002). Brain circulation: how high-skill immigration makes everyone better off. The Brookings Review, v. 20, n. 1, pp. 28-31.

SAYAD, A. (1998). A imigração. São Paulo, Edusp.

TILLY, C. (1976). Migration in Modern European History. Center for Research on Social Organization. Michigan, University of Michigan.

Texto recebido em 30/maio/2017

Texto aprovado em 15/set/2017 
